\title{
Human Enterovirus 71 Disease: Clinical Features, Epidemiology, Virology, and Management
}

\author{
Kow-Tong Chen ${ }^{*}, 1$, Ta-Chung Lee ${ }^{2}$, Hsiao-Ling Chang ${ }^{3,4}$, Mei-Ching Yu ${ }^{5}$ and Li-Hui Tang ${ }^{6}$ \\ ${ }^{I}$ Department of Public Health, College of Medicine, National Cheng Kung University, Taiwan \\ ${ }^{2}$ Department of Rehabilitation, Chiali General Hospital, Tainan, Taiwan. \\ ${ }^{3}$ Division of Surveillance, Center for Disease Control, Department of Health, Taipei, Taiwan \\ ${ }^{4}$ School of Public Health, National Defense Medical Center, National Defense University, Taipei, Taiwan \\ ${ }^{5}$ Department of Chemical Engineering, Tatung University, Taiwan. \\ ${ }^{6}$ Center for Disease Control, Department of Health, Taipei, Taiwan
}

\begin{abstract}
The purpose of this review was to summarize the epidemiology, clinical pictures, and virology of enterovirus 71 (EV71) infection. An epidemiological study in Taiwan revealed that the reported incidence of mild cases of hand-footmouth disease/herpangina (HFMD/HA) varied from year to year; seasonal variations in incidence were observed, with an incidence peak observed during the summer season. The study also showed that different enteroviruses co-circulate in the community, and seroepidemiological studies suggest that children aged less than 4 years old are most susceptible, while over $50 \%$ of the rest of the population is immune. The emergence of the EV71 epidemic in the Asia Pacific region has been associated with the circulation of three genetic lineages (genotype B3, B4, C2) that appear to be undergoing rapid evolutionary changes. EV 71 infection has emerged as an important public problem, causing serious clinical illness and, potentially, death in young children. Vaccine development is recommended for the prevention of EV 71 infection in the future.
\end{abstract}

Keywords: Hand-foot-mouth disease, herpangina, enterovirus 71, pulmonary edema.

\section{INTRODUCTION}

Enteroviruses other than polioviruses, although known to cause outbreaks of a diverse spectrum of diseases often involving the central nervous system (CNS), never attained importance compared to polioviruses. This perception is now changing with more frequent occurrence of enterovirus 71 (EV71) pandemics with fatalities. Because of this virus' potential for causing severe neurologic disease, we need to understand the factors that contribute to its neurovirulence and epidemic potential.

\section{CLINICAL FEATURES}

Epidemics of hand-foot-mouth disease (HFMD) have frequently been associated with Coxsackievirus A16 [1], although EV71 has been increasingly recognized as a cause of this disease. Clinical observations from EV71 epidemics in Japan [2], Taiwan [3] and Western Australia [4] indicate that the HFMD rashes due to Coxsackievirus A16 and EV71 may differ. The rash associated with Coxsackievirus A16 infection is characterized by the formation of larger vesicles than in EV71 infection, in which the rash is more frequently papular and/or petechial, often with areas of diffuse erythema on the trunk and limbs. Because of the high

*Address correspondence to this author at the Department of Public Health, College of Medicine, National Cheng-Kung University, Taiwan. No. 1, University Road, Tainan, Taiwan; Tel: 886-6-2353535, Ext. 5563, Fax: 8866-2359033; E-mail: ktchen@mail.ncku.edu.tw prevalence of HFMD in EV71 disease during the 1998 epidemics in Taiwan [5], there was a tendency in Taiwan to equate EV71 infection with these skin manifestations. However, many outbreaks of EV71 were not associated with HFMD or herpangina (HA) [6,7-11].

In addition to HFMD, EV71 was identified as a cause of HA during epidemics in Hong Kong [12], Japan [13], and Taiwan [5]. HA is a common manifestation of acute Coxsackievirus A infection in young children [14]. EV71associated HA was very prevalent during the Taiwanese epidemic of 1998 [5] and was the second most common diagnosis after HFMD. Approximately $10 \%$ of children with EV71associated neurological disease in Taiwan had an initial concurrent diagnosis of HA [15].

HFMD or HA are important diagnostic indicators of enterovirus infection, but by themselves they are not serious clinical manifestations. The most severe neurological manifestation of EV71 infection is brain stem encephalitis. Ishimaru et al. [16] reported 81 cases with neurological complications from the 1973 and the 1978 EV71 epidemics in Japan. The most common findings were aseptic meningitis and polio-like paresis. Komatsu et al. [2] also described 12 cases from Otsu in 1997, whose primary clinical signs were truncal ataxia, myoclonus, intention tremor, and impaired consciousness. These signs are suggestive of the brain stem, cerebellar and diencephalon involvement.

The Malaysia and Taiwanese outbreaks in the 1990s had both dermatological and neurological features [5,17-19], but 
the major neurological hallmark was that of bulbar involvement. Lum et al. [17] reported four cases with sudden cardiopulmonary collapse and minimal neurological features from the Malaysian epidemic in 1997. Postmortem studies showed infection by EV71 with extensive damage to the medulla and pons.

Chang et al. [18] described the different clinical manifestations of 154 children from northern Taiwan in 1998. They were 11 patients with pulmonary edema, of which 9 had died, 38 patients with CNS involvement but no pulmonary edema and 105 children were without complications. There was a significant association of pulmonary edema with CNS involvement.

Huang et al. [19] described 41 cases of EV 71 infection with neurological complications from southern Taiwan in 1998. All but seven had HFMD or HA. Three had aseptic meningitis and four had acute flaccid paralysis. Thirty-seven had brain stem encephalitis, which the authors divided into three grades. Twenty patients had grade 1 disease, which consisted of myoclonic jerk or tremor, ataxia or both. Ten patients with grade 2 disease had cranial nerve involvement in addition to myoclonus. Seven patients with grade 3 disease had transient myoclonus followed by respiratory distress, cyanosis, poor peripheral perfusion, loss of doll's eye reflex and apnea. All the patients who died were in the grade 3 group and they died within $12 \mathrm{~h}$ after admission. T2weight (T2 W) magnetic resonance imaging (MRI) scans inpatients with brain stem encephalitis showed high intensity lesions in the brain stem, most commonly in the pontine tegmentum.

Acute respiratory disease has been linked to EV71 infection in Australia [20], Canada [21], and Taiwan [22]. Respiratory diseases associated with EV71 infection include pharyngitis, croup, bronchiolitis, and pneumonia [20-22].

Taken together, these data suggested that EV71 can cause $\mathrm{HFMD} / \mathrm{HA}$, CNS involvement with fatal pulmonary edema. Comparing the outbreaks that occurred during different decades, the features of the clinical presentation appear to be changing. The Bulgarian outbreak in 1975 [7,10] had the highest percentage of paralysis $(21 \%)$ but had few dermatological features. The Malaysia and Taiwanese outbreaks in the 1990s had both dermatological and neurological features. These suggest that EV71 strains circulating during specific epidemics vary widely in their dermatotropism and neurotropism, and that these two pathogenetic characteristics of EV71 infection are not rigidly linked.

\section{PATHOGENESIS}

EV71 is a highly neurotropic virus and has been regarded as the most important neurotropic enterovirus after the eradication of the poliovirus [23]. The brain stem is most likely the major target of EV71 infection [5,17-19]. It is likely that many clinically diagnosed cases of EV71-associated acute flaccid paralysis (AFP) are not due to cytopathic damage to anterior horn motor neurons, but are due to other neuropathological mechanisms [24]. As for poliovirus, two possible routes by which the virus reaches the central nervous system (CNS) have been suggested: the virus either enters the CNS from the blood across the blood-brain barrier (BBB), or is transmitted to the CNS through peripheral nerves via retrograde axonal transport $[25,26]$. Expression of certain gene segments would be responsible for determining the capacity of poliovirus to spread to the CNS through the bloodstream or the neuronal pathway [27]. Chen et al. [28] study indicated that EV71 possesses strong neurotropism and that retrograde axonal transport in neuron cells might represent the major transmission route of EV71 in mice.

Wang et al. [29] states that the pulmonary edema that occurs in children with EV71 brain-stem encephalitis is caused by an abnormal cytokine activation that produces a severe inflammatory response, which in turn causes increased pulmonary vascular permeability similar to acute respiratory distress syndrome. Yang et al. [30] have shown that children with severe EV71 encephalitis were significantly more likely to possess a certain cytotoxic $\mathrm{T}$ lymphocyte antigen haplotype (CTLA-4) than children who developed mild EV71 infection.

Although many Malaysian children died from a syndrome of rapidly progressive pulmonary edema [31,32] similar to that observed in Taiwan, a clinical diagnosis of acute myocarditis was made in many cases. In addition, both EV71 and a novel group B adenovirus were isolated from sterile sites and non-sterile sites from both pre-and post-mortem specimens of several fatal cases [31]. However, data currently available in the published literature do not allow a rigorous assessment of the role of adenovirus infection in the pulmonary edema syndrome. It is clear from post-mortem studies of fatal cases in Taiwan [15,19], peninsular Malaysia [17] and Hong Kong [33] that brainstem encephalitis due to EV71 infection is solely sufficient to cause neurogenic pulmonary edema.

\section{EPIDEMIOLOGY OF EV71 INFECTION IN TAIWAN}

\section{Morbidity}

To assess the epidemiological features of EV71 infection, Chen et al. [34] analyzed the data reported to surveillance systems, which was designed for monitoring cases of HFMD and HA, at the Taiwan Center for Disease Control. Fig. (1) shows the number of cases of HFMD/HA reported by sentinel physicians from March 1998 through December 2005. During the 8-year study period, epidemic peaks occurred every year, with the highest number of cases occurring during the summer season. The peak reached a week earlier in the central region and a week and half later in the southern region. The first wave encompassed all four regions of Taiwan. The second wave was largely limited to the southern region, lasting from the first week of September to the second week of December. It peaked during the first week of October. The number of cases reported varied from year to year, with the highest number of cases reported in 1998.

Between 1998 and 2005, a total of 1548 severe cases of HFMD/HA were reported to the Taiwan CDC. The mean age of patients was 2.2 years (range: 3 months to 14 years), and the male-to-female ratio was $1.5: 1$. Most (93\%) of the severe cases of HFMD/HA occurred in children who were four years old or younger, with $75 \%$ occurring in children who were $\leq 2$ years old [35].

\section{Virus Studies}

Viral isolation was performed by 11 reference virus laboratories at medical centers as well as the Taiwan Center for 


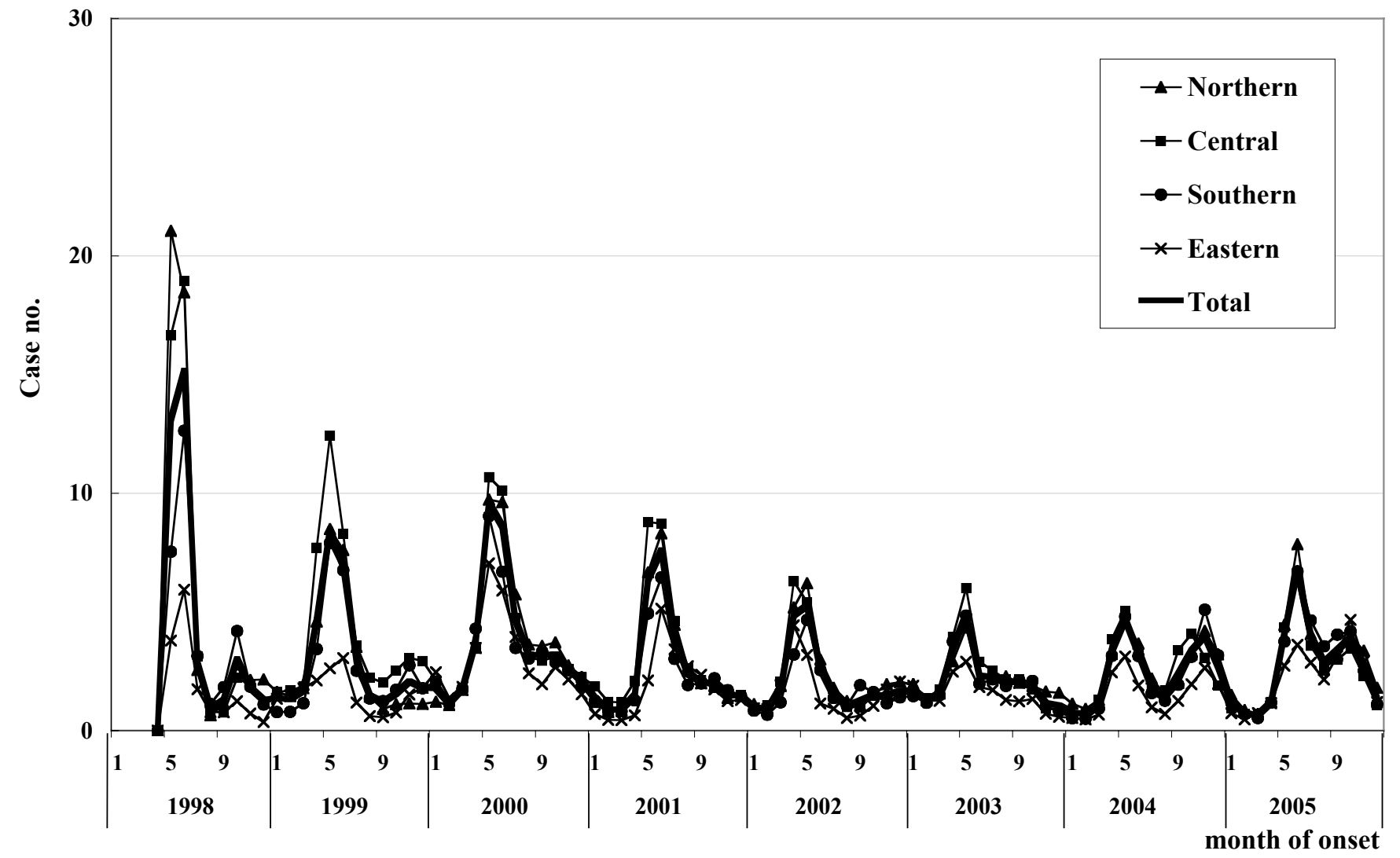

Fig. (1). Number of cases of hand-foot-mouth disease and herpangina reported as a whole and as distinct regions in Taiwan, per sentinel physician, 1998-2005. Note: "total" imply the mean of case numbers of Northern, Central, Southern and Eastern regions. Summarized from Chen KT, et al. 2007 [34].

Disease Control [34-36]. Table 1 shows the data on enteroviruses isolated from outpatients and inpatients with HFMD/HA. During 1998-2005, Coxsackievirus 16 and EV71 were the predominant serotypes. Each of these serotypes accounted for $23 \%$ of reports associated with an identified serotype, followed by Coxsackievirus B3 (13\%), Echovirus 4 (6\%), Coxsackievirus B4 (5\%), and Echovirus 6 $(5 \%)$. This demonstrates the variety of enteroviruses that circulated in the community.

Table 2 shows the clinical complications of 900 hospitalized patients with severe infections between 1998 and 2005 in Taiwan [34]. EV71 was more frequently isolated from patients with encephalitis and pulmonary edema/hemorrhage (93\%). Compared to the frequency of EV71 isolated from patients with aseptic meningitis, there was a significantly increased frequency of EV71 isolated from patients with pulmonary edema/hemorrhage only and encephalitis only. The data suggested that the severity of complications increased with EV71 infection.

Taken together, the data indicated that there are large numbers of other enteroviruses, especially Coxsackievirus A16, cocirculated and their infections were a major contributor to HFMD/HA during EV71 Epidemic in Taiwan. However, EV71 caused almost all the complications of hospitalized patients, particularly those that led to death. This is a useful distinction for the control of outbreaks, because an impending outbreak of clinical import can be detected only by diagnosing EV71 infection virologically, and serious dis- ease and death can be controlled only by preventing or treating EV71 infection.

\section{Seroepidemiology}

Did EV71 circulate in Taiwan before 1998? Was the 1998 epidemic in Taiwan due to the accumulation of susceptible populations? Seroepidemiology of EV71 immediately after the 1998 epidemic was conducted by Chang et al. [37]. Sera collected before the epidemic were available, and serum was collected by investigators for the measurement of postepidemic antibodies immediately after the epidemic. Over $50 \%$ of adults in Taiwan had antibodies against EV71 and were presumably immune to EV71 before the epidemic. Children aged between 0.5 and 3 years old had low antibody levels of $4 \%$ to $26 \%$. The postepidemic seropositive rates of young children were positively correlated with their mortality. This was explained by the protective effect of antibodies present before the epidemic. After the epidemic, a higher antibody rate might have indicated a greater viral load, but there is no further evidence for this hypothesis.

In another study, Lu et al. [38] showed that EV71 antibody in infants and children decreased from $7-11 \%$ to $3-4 \%$ during 1994-1997 preceding the Taiwan 1998 epidemic. It is possible that the drop in protective antibody led to the increase in EV71 infection on a large scale. Some studies, however, have found there was no difference in neutralizing antibody titers in children with or without EV71 meningoencephalitis [30]. 
Table 1. Percentage Distribution of the 21 Most Commonly Reported Non-Polio Enterovirus Serotypes, Taiwan, $1998-2005$

\begin{tabular}{|c|c|c|c|c|c|c|c|c|c|}
\hline Serotypes & $\begin{array}{c}1998 \\
N=194\end{array}$ & $\begin{array}{c}1999 \\
N=224\end{array}$ & $\begin{array}{c}2000 \\
N=983\end{array}$ & $\begin{array}{c}2001 \\
N=1569\end{array}$ & $\begin{array}{c}2002 \\
N=1164\end{array}$ & $\begin{array}{c}2003 \\
N=1134\end{array}$ & $\begin{array}{c}2004 \\
N=759\end{array}$ & $\begin{array}{c}2005 \\
\mathbf{N}=\mathbf{2 0 0 3}\end{array}$ & $\begin{array}{c}\mathbf{1 9 9 8 - 2 0 0 5} \\
\mathbf{N}=\mathbf{8 0 3 0}\end{array}$ \\
\hline CAV2 & 16 & & & & 1 & 12 & & & 2 \\
\hline CAV4 & 8 & & & & 10 & & 1 & 1 & 2 \\
\hline CAV5 & & & & & & 10 & 1 & & 2 \\
\hline CAV6 & 7 & & & 1 & & 11 & 1 & & 2 \\
\hline CAV9 & & & 2 & 2 & & & 4 & 2 & 1 \\
\hline CAV10 & 3 & 12 & & & 6 & 2 & 1 & & 2 \\
\hline CAV12 & & & & & & 1 & & & \\
\hline CAV16 & 11 & 8 & 25 & 21 & 21 & 40 & 5 & 24 & 23 \\
\hline CAV24 & & 5 & 1 & 1 & 4 & & & & 1 \\
\hline CBV1 & & 15 & 2 & & & & & & 1 \\
\hline CBV2 & & 15 & & & 3 & 3 & & 3 & 2 \\
\hline CBV3 & & 34 & 10 & & & & 6 & 40 & 13 \\
\hline CBV4 & & 2 & 6 & 3 & & & 39 & & 5 \\
\hline CBV5 & 2 & 2 & & 1 & 12 & 2 & & & 2 \\
\hline ECHO4 & 2 & 4 & 3 & 29 & 1 & & 1 & & 6 \\
\hline ECHO5 & 6 & & & & & & & & \\
\hline ECHO6 & & & & 14 & 20 & & & & 5 \\
\hline ECHO7 & 2 & & & & & & & & \\
\hline ECHO9 & & & 14 & & & & 2 & 5 & 3 \\
\hline ECHO11 & & & & & & 12 & 3 & & 2 \\
\hline EV71 & 37 & 3 & 35 & 28 & 16 & 3 & 30 & 20 & 23 \\
\hline Total* & 94 & 100 & 98 & 100 & 94 & 96 & 94 & 95 & 97 \\
\hline
\end{tabular}

CAV, Coxsackie A virus; CBV, Coxsackie B virus; ECHO, Echo virus.

* Totals might be slightly different from sums of percentages because of rounding. All other serotypes were $6 \%$ in $1998,2 \%$ in $2000,6 \%$ in $2002,4 \%$ I $2003,6 \%$ in $2004,5 \%$ in 2005 .

Summarized from Chen KT, et al. 2007 [34].

\section{Transmission}

Transmission of EV71 infection is a public concern. In a prospective family cohort study [39], the rate of household transmission of EV71 infection was $52 \%$. The rate of transmission among household children was particularly high at
84\%. The most important factor in EV71 transmission was intrafamily transmission, especially the presence of an older sibling who was seropositive. McMinn [40] showed that most cases with severe infection had a history of contact with an infected sibling, and this may suggest a role for increased viral exposure of infective dose of EV71.

Table 2. Clinical Complications in 900 Patients with Severe, Culture-Proven, Enteroviral Infection, 1998-2005

\begin{tabular}{|l|c|c|c|c|}
\hline \multicolumn{1}{|c|}{ Complications* } & No. of Patients N=900 & EV71 N (\%) N= 594 & Other Enterovirus N=306 & Odds Ratio (95\% CI) \\
\hline \hline Aseptic meningitis only & 120 & $42(39)$ & $78(45)$ & Referent \\
\hline Encephalitis only & 371 & $233(7)$ & $138(26)$ & $3.14(2.00-4.94)^{*}$ \\
\hline Pulmonary edema or hemorrhage only & 90 & $68(11)$ & $7(2)$ & $5.74(2.99-11.09)^{*}$ \\
\hline Myocarditis only & 11 & $4(1)$ & $8(3)$ & $1.06(0.24-4.36)$ \\
\hline Acute flaccid paralysis only & 11 & $3(1)$ & $22(7)$ & $0.70(0.14-3.11)$ \\
\hline Combined & 236 & $214(36)$ & $31(10)$ & $18.06(9.78-33.65)^{*}$ \\
\hline Other & 61 & $30(5)$ & $1.80(0.92-3.53)$ \\
\hline
\end{tabular}

Note. Data are no. (\%) of patients, except where noted; the categories of complications are mutually exclusive; EV71, enterovirus $71 ;{ }^{*} \mathrm{P}<0.001$.

Summarized from Chen KT, et al. 2007 [34]. 
Table 3. Summary of Human Enterovirus 71 Genotypes Circulating in the Asia-Pacific Region, 1997-2005

\begin{tabular}{|c|c|c|c|c|c|c|}
\hline & Singapore & Malaysia & Australia & Japan & Korea & Taiwan \\
\hline \hline 1997 & B3, B4 & B3, B4 & B3 & B3, B4, C2 & -- \\
\hline 1998 & B3, C1 & C1, B4 & B3 & -- & C2, B4 \\
\hline 1999 & B3 & -- & B3, C2 & -- & B4 \\
\hline 2000 & B4 & B4, C1 & C1 & B4, C2 & C3 & B4 \\
\hline 2001 & B4 & B4, C1 & -- & C2 & B4 \\
\hline 2002 & C1, B4 & & -- & C4 & B4 \\
\hline 2003 & -- & C1, B4, B5 & C1 & B4, B5, C4 & B4 \\
\hline 2004 & -- & -- & -- & -- & C4 \\
\hline 2005 & -- & -- & -- & C4 \\
\hline
\end{tabular}

Bold type indicates predominant; --, no data available.

\section{MOLECULAR EPIDEMIOLOGY}

There has been a great deal of interest in trying to explain the spread and virulence of EV71 in molecular and genetic terms. Table 3 shows the phylogenetic origins of EV71 strains recently circulating in the Asia-Pacific region [4153].

Using protein VP1 for analysis, three distinct EV71 genotypes (A, B, and C) were identified [47]. The original prototype from California ( $\mathrm{BrCr}$ strain) is the sole representative of genotype A, whilst genotype B was the main viral strain in circulation during the 1970 s and 1980 s, but disappeared from the USA after 1988 to be replaced with genotype $\mathrm{C}$, which has been co-circulated with genotype $\mathrm{B}$ in the rest of the world since 1985. The co-circulation of four distinct genogroups (B3, B4, C1, C2) in Malaysia between 1997-2000 has been well documented. In particular, B3 and B4 were identified as the major causes of the EV71 epidemic in Malaysia during 1997, while C1 and B4 were responsible for the 2000 epidemic [50]. Singapore and Western Australia were also affected by the B3 genogroup during 1997-1999 [40].

Comparison of VP1 sequences from isolates involved in the 1998 epidemic in Taiwan showed that the majority of strains belonged to the $\mathrm{C} 2$ genogroup, and a minority to the B genogroup [43,51]. During the next two years, a significant genotype shift occurred and B4 became the predominant genogroup in the 2000 outbreak in Taiwan [48]. Genogroup C was not reported again in the region until 2004, where it emerged as a previously unrecognized $\mathrm{C} 4$ genogroup, based on a short-region VP4 analysis [44]. A C4 genogroup EV71 has also been isolated recently from sporadic infections in Mainland China [54].

Overall, the epidemics in South East Asia and Western Australia raised important questions about the biology of EV71, and its mode of spread and swift genogroup replacement [55]. The presence of four genogroups circulating at one time-point in Malaysia suggests the region could be serving as the endemic focus of EV71, which may facilitate close interaction between EV71 isolates and other enteroviruses, thus allowing inter-viral genetic exchanges.
We do not know enough about the relationship between the gene structure of the virus and the factors that ensure its survival, such as virulence, ease of transmission and evasion of immunity. Why did they produce pandemics in Malaysia and Taiwan but not in Japan? Since the viruses were similar, unknown ecological and environmental factors were presumably at work $[49,53]$.

EV 71 has high mutability, in constant evolution with an estimated variation rate of $1.35 \times 10^{-2}$ substitutions per nucleotide, similar to that observed for poliovirus [47]. However, to what extent the genetic exchanges explain biologi$\mathrm{cal} /$ epidemic behavior is open to debate. There were examples of both genotypes B and C being associated with complicated and uncomplicated disease [45,49], thus making it difficult to pinpoint a virus-specific marker of virulence. EV71 lacks the use of a DNA template for correcting mismatches, resulting in an average of one mutation per new genome copy [56]. Furthermore, genomic recombination is frequently used amongst enteroviruses as a mechanism to produce variants [57], presumably as a response to selection pressure [58]. Taken together, these observations suggest that recombination and mutation may benefit the spread of EV71 in the human population [59].

\section{STRAINS AND PHENOTYPIC VARIATIONS}

Based on the definition established by Brown et al. [47], it is recognized that within the same genotype the total variation between strains should not exceed $12 \%$, while strains belonging to two different genotypes may display a variation in the range of $16-19 \%$. It is evident from phylogenetic tree analyses that two of the major epidemics in 1990s, namely Malaysia 1997 and Taiwan 1998, were caused by quite different prevalent strains [43-46]. However, on the whole, studies have been largely unsuccessful at attributing phenotypic variations to subtype differences.

Nucleotide sequence analysis of different regions of the EV71 genome reveals heterogeneity of isolates, not only geographically but also temporally. Major changes can be seen when comparing isolates from before and after 1985 in the United States, and isolates from Japan in the 1970's and in 1997. Isolates from Japan, Malaysia and Taiwan in 1997 and 1998 are clearly related, and are segregated in Shimizu's genotypes A-2 and B [49]. It is unclear in which of these 
three countries these two genotype strains originated. No clear marker of neurovirulence or any other clinical manifestation has so far been identified.

\section{TREATMENT}

Pyridyl imidazolidinone is a novel class of capsid binder, which can inhibit EV71 [60]. Chen et al. [61] evaluated the potential interaction between Pyridyl imidazolidinone with the EV71 VP1 protein. Mutations at D31N or E98K in VP1 may widen the hydrophobic pocket of VP1, allowing bulkier compounds to enter and interfere with VP1-receptor binding.

A cytokine-mediated process was shown to contribute to the development of pulmonary edema [29]. Milrinone, a bipyridine derivative that specifically inhibits cyclic nucleotide phosphodiesterase (PDE) inhibitor, was used for the treatment of severe EV71 infection with pulmonary edema [23]. Wang et al. [62] evaluated the potential effect of milrinone in the treatment of patients with EV71-induced pulmonary edema. The mortality was lower, and marked decreases in the level of IL-13 in the milrinone-treated vs non-treated group were observed.

In 2000, Taiwan developed a disease-management program to improve the survival rate of patients with EV71 infection $[23,63]$. Although that program led to a reduction of acute mortality [54], concerned about long-term sequelae remains.

Nevertheless, there is no proven effective therapy for EV71 disease. Antiviral, steroidal, and intravenous immunoglobulin therapy have all been used for EV71 infection, but these treatments have not been studied in randomized, placebo-controlled trials [4,19].

\section{CONCLUSIONS}

There has been a significant increase in EV71 epidemic activity in the Asia-Pacific region in last 10 years. The as yet unexplained hallmark pulmonary edema or hemorrhage is now considered to be an autonomic nervous system manifestation of brain stem encephalitis, traceable to the neurotropism typical of classical enterovirus. Molecular generic studies of EV71 isolates indicate that four distinct viral genotypes have circulated in the Asia-Pacific region between 1997 and 2005. Understanding the the host and environmental factors, molecular genesis of EV71 virulence, and vaccine development are needed for the prevention of epidemic of EV71 infections.

\section{REFERENCES}

[1] Melnick JL. Enterovirus: polioviruses, Coxsackieviruses, echoviruses and new enteroviruses. In: Virology (Fields BN, Knipe DM, Howley PM, et al. eds), Chapter 22, 1996; pp 655-712.

[2] Komatsu H, Shimizu Y, Takeuchi Y, Ishiko H, Takada H. Outbreak of severe neurologic involvement associated with enterovirus 71 infection. Pediatr Neurol 1999; 20: 17-23.

[3] Chang LY, Lin TY, Huang YC, et al. Comparison of enterovirus 71 and Coxsackievirus A 16 clinical illness during the Taiwan enterovirus epidemic. Pediatr Infect Dis J 1998; 18: 1092-6.

[4] McMinn P, Stratov I, Nagarajan L, Davis S. Neurological manifestations of enterovirus 71 infection in children during an outbreak of hand, foot, mouth disease in western Australia. Clin Infect Dis 2001; 32: 236-42

[5] Ho M, Chen ER, Hsu KH, et al. The enterovirus type 71 epidemic of Taiwan, 1998. N Engl J Med 1999; 341: 929-35.
Schmidt NJ, Lennett EH, Ho HH. An apparently new enterovirus isolated from patients with disease of the central nervous system. J Infect Dis 1974; 129: 304-9.

[7] Chumakov M, Voroshilova M, Shindarov L, et al. Enterovirus 71 isolated from cases of epidemic poliomyelitis-like disease in Bulgaria. Arch Virol 1979; 60: 329-40.

[8] Deibel R, Gross LL, Collins DN. Isolation of a new enterovirus. Proc Soc Exp Biol Med 1975; 148: 203-7.

[9] Blomberg J, Lycke E, Ahlfors K, et al. New enerovirus type associated with epidemic of aseptic meningitis and/or hand, foot, and mouth disease. Lancet 1974; 2: 112.

[10] Shindarov LM, Chumakov MP, Voroshilova MK, et al. Epidemiological, clinical, and pathomorphological characteristics of epidemic poliomyelitis-like disease caused by enterovirus 71. J Hyg Epidemiol Microbiol Immunol 1979; 23: 284-95.

[11] Nagy G, Takatsy S, Kukan E, Mihaly I, Domok I. Virological diagnosis of enterovirus type 71 infections: experiences gained during an epidemic of acute CNS diseases in Hungary in 1978. Arch Virol 1982; 71: 217-27.

[12] Samuda GM, Chang WK, Yeug CY, et al. Monoplegia caused by enterovirus 71: an outbreak in Hong Kong. Pediatr Infect Dis J 1987; 6: 206-8

[13] Hagiwara A, Tagaya I, Yoneyama T. Epidemic of hand, foot and mouth disease associated with enterovirus 71 infection. Intervirology 1978; 9: 60-3.

[14] Collier L, Balows A, Sussrnan M, Miner P. Picornaviruses. In: Mary BWJ, Collier L, eds. Topley and Wilson's Microbial Infections. 9th ed. Vol I. London: Edward Arnold 1998; 485-509.

[15] Wang SM, Liu CC, Tseng HW, et al. Clinical spectrum of enterovirus 71 infection in children in southern Taiwan, with an emphasis on neurological complications. Clin Infect Dis 1999; 29: 184-90.

[16] Ishimaru Y, Nakano S, Yamaoka K, Takami S. Outbreak of hand foot, and mouth disease by enterovirus 71 . High incidence of complication disorders of central nervous system. Arch Dis Child 1980; 55: 583-8.

[17] Lum LCS, Wong KT, Lam SK, et al. Fatal enterovirus 71 encephalomyelitis. J Pediatr 1998; 133: 795-8.

[18] Chang LY, Lin TY, Hsu KH, et al. Clinical features and risk factors of pulmonary oedema after enterovirus 71-related hand, foot, and mouth disease. Lancet 1999; 354: 1682-6.

[19] Huang CC, Liu CC, Chang YC, et al. Neurologic complications in children with enterovirus 71 infection. N Engl J Med 1999; 341: 936-42.

[20] Gilbert GL, Dickson KE, Waters MJ, Kennett ML, Land SA, Sneddon M. Outbreak of enterovirus 71 in Victoria, Australia, with a high incidence of neurogenic involvement. Pediatr Infect Dis J 1988; 7: 484-8.

[21] Merovitz L, Demers AM, Newby D, McDonald J. Enterovirus 71 infections at a Canadian center. Pediatr Infect Dis J 2000; 19: 755 7.

[22] Tsai HP, Kuo PH, Liu CC, Wang JR. Respiratory virus infections among pediatric inpatients and outpatients in Taiwan from 1997 to 1999. J Clin Microbiol 2001; 39: 111-8.

[23] Lin TY, Chang LY, Hsia SH, et al. The 1998 enterovirus 71 outbreak in Taiwan: pathogenesis and management. Clin Infect Dis 2002; 34: s52-s57.

[24] Ramos-Alvarez M, Bessudo L, Sabin AB. Paralytic syndromes associated with non-inflammatory cytoplasmic or nuclear neuropathology: acute paralytic disease in Mexican children, neuropathologically distinguishable from Landry-Guillain-Barré syndrome. JAMA 1969; 207: 1481-92.

[25] Crotty S, Hix L, Sigal LJ, Andino R. Poliovirus pathogenesis in a new poliovirus receptor transgenic mouse model: age-dependent paralysis and a mucosal route of infection. J Gen Virol 2002; 83: 1707-20.

[26] Ohka S, Matsuda N, Tohyama K, et al. Receptor (CD155)dependent endocytosis of poliovirus and retrograde axonal transport of the endosome. J Virol 2004; 78: 7186-98.

[27] Tyler KL, McPhee DA, Fields BN. Distinct pathways and viral spread in the host determined by reovirus S1 gene segment. Science 1986; 233: 770-4

[28] Chen CS, Yao YC, Lin SC, et al. Retrograde axinal transport: a major transmission route of enterovirus 71 in mice. J Virol 2007; 81: 8996-9003

[29] Wang SM, Lei HY, Huang KJ, et al. Pathogenesis of enterovirus 71 brainstem encephalitis in pediatric patients: the roles of cytoki- 
nes and cellular immune activation in patients with pulmonary edema. J Infect Dis 2003; 188: 564-70.

[30] Yang KD, Yang MY, Li CC, et al. Altered cellular but not humoral reactions in children with complicated enterovirus 71 infections in Taiwan. J Infect Dis 2001; 183: 850-6.

[31] Cardosa MJ, Krishnan S, Tio PH, Perera D, Wong SC. Isolation of subgenus B adenovirus during a fatal outbreak of enterovirus 71associated hand, foot, and mouth disease in Sibu, Sarawak. Lancet 1999; 354: 987-91.

[32] Chan LG, Parashar UD, Lye MS, et al. Deaths of children during an outbreak of hand, foot, and mouth disease in Sarawak, Malaysia : Clinical and pathological characteristics of the disease. Clin Infect Dis 2000; 31: 678-83.

[33] Ng DK, Law AK, Cherk SWW, Mak KL. First fatal case of enterovirus 71 infection in Hong Kong. Hong Kong Med J 2001; 7: 1936.

[34] Chen KT, Chang HL, Wang ST, Cheng YT, Yang JY. Epidemiologic features of hand-foot-mouth disease and herpangina caused by enterovirus 71 in Taiwan, 1998-2005. Pediatrics 2007; 120: e244-52.

[35] Chen SC, Chang HL, Yan TR, Cheng YT, Chen KT. An eight-year study of epidemiologic features of enterovirus 71 infection in Taiwan. Am J Trop Med Hyg 2007; 77: 188-91.

[36] Tseng FC, Huang HC, Chi CY, et al. Epidemiological survey of enterovirus infections occurring in Taiwan between 2000 and 2005: analysis of sentinel physician surveillance data. J Med Virol 2007; 79: $1850-60$

[37] Chang LY, King CC, Hsu KH, et al. Risk factors of enterovirus 71 infection and associated hand, foot, and mouth disease/ herpangina in children during an epidemic in Taiwan. Pediatrics 2002; 109: e88.

[38] Lu CY, Lee CY, Kao CL, et al. Incidence and case-fatality rates resulting from the 1998 enterovirus 71 outbreak in Taiwan. J Med Virol 2002; 67: 217-23.

[39] Chang LY, Tsao KC, Hsia SH, et al. Transmission and Clinical features of enterovirus 71 infections in household contacts in Taiwan. JAMA 2004; 291: 222-7.

[40] McMinn P, Lindsay K, Perera D, Chan HM, Chan KP, Cardosa MJ. Phylogenetic analysis of enterovirus 71 strains isolated during linked epidemics in Malaysia, Singapore, and Western Australia. J Virol 2001; 75: 7732-8.

[41] Singh S, Chow VT, Chan KP, Ling AE, Poh CL. RT-PCR, nucleotide, amino acid and phylogenetic analyses of enterovirus type 71 strains from Asia. J Virol Methods 2000; 88: 193-204.

[42] Chu PY, Lin KH, Hwang KP, et al. Molecular epidemiology of enterovirus 71 in Taiwan. Arch Virol 2001; 146: 589-600.

[43] Cardosa MJ, Perera D, Brown BA, et al. Molecular epidemiology of human enterovirus 71 strains and recent outbreaks in the AsiaPacific region: comparative analysis of the VP1 and VP4 genes. Emerg Infect Dis 2003; 9: 461-8.

[44] Lin KH, Hwang KP, Ke GM, et al. Evolution of EV71 genogroup in Taiwan from 1998 to 2005: an emerging of subgenogroup C4 of EV71. J Med Virol 2006; 78: 254-62.

[45] Shih SR, Ho MS, Lin KH, et al. Genetic analysis of enterovirus 71 isolated from fatal and nonfatal cases of hand, foot and mouth disease during an epidemic in Taiwan. Virus Res 2000; 68: 127-36.
[46] AbuBakar S, Chee HY, Al-Kobaisi MF, Xiaoshan J, Chua KB, Lam SK. Identification of enterovirus 71 isolates from an outbreak of hand, foot and mouth disease (HFMD) with fatal cases of encephalomyelitis in Malaysia. Virus Res 1999; 61: 1-9.

[47] Brown BA, Oberste MS, Alexander JP Jr, Kennett ML, Pallansch MA. Molecular epidemiology and evolution of enterovirus 71 strains isolated from 1970 to 1998. J Virol 1999; 73: 9969-75.

[48] Wang JR, Tuan YC, Tsai HP, Yan JJ, Liu CC, Su IJ. Change of major genotype of enterovirus 71 in outbreaks of hand-foot-andmouth disease in Taiwan between 1998 and 2000. J Clin Microbiol 2002; 40: 10-5.

[49] Shimizu H, Utama A, Yoshii K, et al. Enterovirus 71 from fatal and nonfatal cases of hand, foot and mouth disease epidemics in Malaysia, Japan and Taiwan in 1997-1998. Jpn J Infect Dis 1999; 52: $12-5$.

[50] Herrero LJ, Lee CS, Hurrebrink RJ, Chu BH, Chua KB, McMinn PC. Molecular epidemiology of enterovirus 71 in peninsular Malaysia, 1997-2000. Arch Virol 2003; 148: 1369-85.

[51] Kung SH, Wang SF, Huang CW, Hsu CC, Liu HF, Yang JY. Genetic and antigenic analyses of enterovirous 71 isolates in Taiwan during 1998-2005. Clin Microbiol Infect 2007; 13: 782-7.

[52] Ooi MH, Wong SC, Podin Y, et al. Human enterovirus 71 disease in Sarawak, Malaysia : A prospective clinical, virological, and molecular epidemiology study. Clin Infect Dis 2007; 44: 646-56.

[53] Hosoya M, Kawasaki Y, Sato M, et al. Genetic diversity of enterovirus 71 associated with hand, foot and mouth disease epidemics in Japan from 1983 to 2003. Pediatr. Infect Dis J 2006; 25: 691-4.

[54] Li L, He Y, Yang H, et al. Genetic characteristics of human enterovirus 71 and cozsackievirus A16 circulating from 1999 to 2004 in Shenzhen, People's Republic of China. J Clin Microbiol 2005; 43: 3835-9.

[55] McMinn PC. An overview of the evolution of enterovirus 71 and its clinical and public health significance. FEMS Microbiol Rev 2002; 26: 91-107.

[56] Drake JW, Holland JJ. Mutation rates among RNA viruses. Proc Natl Acad Sci USA 1999; 96: 13910-3.

[57] Santti J, Hyypia T, Kinnunen L, Salminen M. Evidence of recombination among enteroviruses. J Viol 1999; 73: 8741-9.

[58] Halim S, Ramsingh AI. A point mutation in VP1 of Coxsackievirus B4 alters antigenicity. Virology 2000; 269: 86-94.

[59] Bible JM, Pantelidis P, Chan PKS, Tong CYW. Genetic evolution of enterovirrus 71: epidemiological and pathological implications. Rev Med Virol 2007; 17: 371-9.

[60] Pevear DC, Tull TM, Seipel ME, Groarke JM. Activity of pleconaril against enteroviruses. Antimicrob Agents Chemother 1999; 43: 2109-15.

[61] Chen TC, Liu SC, Huang PN, Chang HY, Chern JH, Shih SR. Antiviral activity of pyridyl imidazolidinones against enterovirus 71 variants. J Biomed Sci 2008 (in press).

[62] Wang SM, Lei HY, Haung MC, et al. Therapeutic efficacy of Milrinone in the management of enterovirus 71-induced pulmonary edema. Pediatr Pulmonary 2005; 39: 219-23.

[63] Chang LY, Hsia SH, Wu CT, et al. Outcome of enterovirus 71 infections with or without stage-based management: 1998 to 2002 . Pediatr Infect Dis J 2004; 23: 327-32.

(C) Chen et al.; Licensee Bentham Open.

This is an open access article distributed under the terms of the Creative Commons Attribution License (http://creativecommons.org/licenses/by/2.5/), which permits unrestrictive use, distribution, and reproduction in any medium, provided the original work is properly cited. 